\title{
Ambulance use is not associated with patient acuity after road traffic collisions: a cross-sectional study from Addis Ababa, Ethiopia
}

Yonas Abebe ${ }^{1 *}\left(\mathbb{D}\right.$, Tolesa Dida ${ }^{1}$, Engida Yisma ${ }^{2,3}$ and David M. Silvestri ${ }^{4}$

\begin{abstract}
Background: Africa accounts for one sixth of global road traffic deaths-most in the pre-hospital setting. Ambulance transport is expensive relative to other modes of pre-hospital transport, but has advantages in time-sensitive, high-acuity scenarios. Many countries, including Ethiopia, are expanding ambulance fleets, but clinical characteristics of patients using ambulances remain ill-defined.

Methods: This is a cross-sectional study of 662 road traffic collisions (RTC) patients arriving to a single trauma referral center in Addis Ababa, Ethiopia, over 7 months. Emergency Department triage records were used to abstract clinical and arrival characteristics, including acuity. The outcome of interest was ambulance arrival. Secondary outcomes of interest were inter-facility referral and referral communication. Descriptive and multivariable statistics were computed to identify factors independently associated with outcomes.

Results: Over half of patients arrived with either high (13.1\%) or moderate (42.2\%) acuity. Over half (59.0\%) arrived by ambulance, and nearly two thirds (65.9\%) were referred. Among referred patients, inter-facility communication was poor (57.7\%). Patients with high acuity were most likely to be referred (aOR 2.20, 95\%Cl 1.16-4.17), but were not more likely to receive ambulance transport (aOR $1.56,95 \% \mathrm{Cl} 0.86-2.84$ ) or inter-facility referral communication (aOR $0.98,95 \% \mathrm{Cl} 0.49-1.94$ ) than those with low acuity. Nearly half (40.2\%) of all patients were referred by ambulance despite having low acuity.

Conclusions: Despite ambulance expansion in Addis Ababa, ambulance use among RTC patients remains heavily concentrated among those with low-acuity. Inter-facility referral appears a primary contributor to low-acuity ambulance use. In other contexts, similar routine ambulance monitoring may help identify low-value utilization. Regional guidelines may help direct ambulance use where most valuable, and warrant further evaluation.
\end{abstract}

Keywords: Ethiopia, Africa, Trauma, Road traffic collisions, Road traffic accident, Road traffic injury, Ambulance, Pre-hospital, Triage acuity, Referral

\footnotetext{
* Correspondence: yonbbb@gmail.com

${ }^{1}$ Department of Emergency and Critical Care Nursing, St. Paul's Hospital

Millennium Medical College, Addis Ababa, Ethiopia

Full list of author information is available at the end of the article
}

(c) The Author(s). 2018 Open Access This article is distributed under the terms of the Creative Commons Attribution 4.0 International License (http://creativecommons.org/licenses/by/4.0/), which permits unrestricted use, distribution, and reproduction in any medium, provided you give appropriate credit to the original author(s) and the source, provide a link to the Creative Commons license, and indicate if changes were made. The Creative Commons Public Domain Dedication waiver (http://creativecommons.org/publicdomain/zero/1.0/) applies to the data made available in this article, unless otherwise stated. 


\section{Background}

Worldwide, road traffic collisions (RTC) are a leading cause of preventable morbidity and mortality. Each year, more than 1.2 million people die from RTC globally-one every thirty seconds-and as many as 50 million more incur non-fatal injuries [1,2]. This burden is borne disproportionately by low- and middle-income countries (LMIC). Although Africa has just 2\% of the world's vehicles, it accounts for $16 \%$ of global road traffic deaths [1].

The World Health Organization has highlighted several key interventions for the prevention of RTC, including notably laws and regulations to improve driver, vehicle, and road safety [1]. Nevertheless, in conjunction with such prevention efforts, quick and effective emergency health systems are needed to limit resultant morbidity and mortality after RTC. This starts with rapid and appropriate pre-hospital care and transport. In LMIC, it is estimated that $80 \%$ of road traffic deaths occur before patients even reach a hospital [3]. Although much of this mortality may be attributed to rural regions, where collision speeds are often higher and transport times longer [4], pre-hospital delays remain a significant contributor to excess road traffic mortality in urban contexts as well, despite increased ambulance availability [5].

As pre-hospital systems become more widely available in LMIC, attention is needed to ensure appropriate use of limited ambulance services. Many types of prehospital care and transport systems have been described in low-income contexts [6]. Care by formally trained pre-hospital personnel and transport by equipped ambulances is relatively expensive and remains scarce compared to other lower-resource approaches (e.g., modified motorcycles), but has advantages in certain timesensitive and high-acuity scenarios [6]. In sub-Saharan Africa, a minority of urban RTC patients arrive by ambulance $[7,8]$, but the precise populations receiving such pre-hospital care and transport remain ill-defined.

To address this important research gap, we aim to describe the characteristics of RTC patients arriving by ambulance at a single urban public trauma center in Addis Ababa, Ethiopia. Addis Ababa is the capital and largest city in Ethiopia, Africa's second most populous nation. As elsewhere in Africa, RTC are a growing problem in Ethiopia, causing nearly 3500 fatalities annually and costing $1 \%$ of gross domestic product [1]. The distribution of injuries, interventions, and outcomes of RTC patients in Addis Ababa have been described [8]. Although many of these patients arrive from the scene, a large percent are referred from primary health centers or hospitals without specific trauma care capabilities. Understanding which patients receive ambulance transport, including those referred for higher levels of care, may help identify opportunities for targeted trauma system resource allocation.

\section{Methods}

\section{Study design, setting, and population}

We performed a retrospective chart review of all adult and pediatric patients arriving after RTC to Addis Ababa Burn Emergency and Trauma (AaBET) Hospital from August 22nd 2015 to March 9th 2016 (7 months). AaBET Hospital is a newly established 250-bed and 12 ICU-bed teaching and public referral hospital in Addis Ababa, Ethiopia, affiliated with St. Paul's Hospital Millennium Medical College (SPHMMC). AaBET Hospital provides $24 / 7$ specialty services in emergency medicine, critical care, trauma and acute care surgery, orthopedics, neurosurgery, and forensic medicine; patients presenting with complaints requiring additional specialty services (e.g., cardiology, gastroenterology) are stabilized and transferred to nearby SPHMMC.

All patients presenting to the AaBET Hospital emergency department (ED) pass through a single point of triage, where trained emergency triage nurses record essential clinical and demographic information and assign a triage acuity designation according to the South African Triage Scale (SATS) [9]. The SATS has been validated for use in diverse low-income urban adult and pediatric ED settings, [10-13] and has high reported inter-rater reliability among emergency nurses $(\kappa=0.92),[14,15]$ and in trauma settings [16]. It is currently used in all public EDs in Addis Ababa. Patients are categorized into five priority levels (emergent, very urgent, urgent, routine, dead on arrival) based on clinical instability, vital signs, and presenting complaint [10].

\section{Data collection and analysis}

Patient triage records were included for analysis if they were complete or partially complete. AaBET Hospital employs a hand-written triage and medical record system. All information was entered electronically into a standardized abstraction form by trained transcriptionists clinically trained in emergency care nursing and blinded to the intended analysis, in accordance with recommended best practice for retrospective chart reviews [17]. Subsequently, an audit was performed to ensure a low rate of data entry error.

Variables abstracted for analysis from triage records included patient age and sex, date of arrival to ED (weekday, weekend), patient origin (Addis Ababa, outside Addis), mode of arrival to ED (ambulance, taxi or private car, ambulatory or carried), triage acuity, referral status and source of referral (government hospital, health center, private institution), and whether communication had been received from referring institutions prior to patient arrival. Descriptive statistics were calculated for all variables. Triage acuity scores were grouped into three categories: low (routine), moderate (urgent), or high (very urgent, emergent, dead on arrival). Children were considered less than 13 years, in 
conjunction SATS validation [13]. We used simultaneous multivariable logistic regression to identify factors (selected a priori) independently associated with arrival by ambulance, the primary outcome of interest. Subsequent regressions were performed to determine factors associated with inter-facility referral and inter-facility referral communication, which were secondary outcomes of interest. Missing data were accounted for using multiple imputation, and all statistical analysis was performed using SPSS version 21.0.0 (IBM Corporation, 2012).

\section{Results}

\section{Population characteristics}

During the seven-month study period, a total of 2062 patients were evaluated after trauma in AaBET Hospital ED. RTC accounted for 662 patients (32\%), of which all had complete or partially complete triage records and were included in analysis. Two thirds of RTC patients were male (66.2\%), with a median age of 27 years (Table 1). Children less than 13 accounted for a minority (4.8\%) of all RTC cases. Most patients (72.4\%) were seen on weekdays, with over half originating from outside Addis Ababa city limits (60.6\%). Nearly half were assigned low (routine) triage acuity upon arrival (44.7\%), while $42.2 \%$ were designated as moderate and another $13.1 \%$ as high acuity $-9.0 \%$ as very urgent, $3.8 \%$ as emergent, and two patients $(0.3 \%)$ dead on arrival.

\section{Inter-facility referral}

Most RTC patients (65.9\%) were referred to AaBET Hospital from outside institutions (Table 1), with government hospitals comprising the single largest source of referral $(42.5 \%$ of all RTC patients and $64.5 \%$ of total RTC referrals) and outpatient health centers referring one fifth (20.3\%) of all RTC patients. As might be expected, the frequency of referral differed when accounting for patient origin. Among patients arriving from Addis Ababa, over half $(138 / 249 ; 55.4 \%)$ arrived from the scene without any prior referral, whereas 80\% (292/365) of patients from outside Addis Ababa were referred via another institution (Table 2). In fact, independent of other characteristics, patients arriving from within Addis Ababa were nearly five times less likely to be referred than peers originating from outside the city (aOR $0.22,95 \% \mathrm{CI} 0.15-0.32$ ). Sicker patients were independently more likely to have been referred to AaBET Hospital after RTC. Patients with high and moderate triage acuity were more likely to be referred compared to those with low acuity (High: aOR 2.20, 95\%CI 1.16-4.17; Moderate: aOR 1.55, 95\% 1.05-2.28). Neither patient age nor sex was associated with increased odds of referral.
Table 1 Characteristics of patients presenting after RTC to AaBET Hospital, Addis Ababa

\begin{tabular}{|c|c|}
\hline Characteristic & $\begin{array}{l}\text { Total } \\
(n=662)\end{array}$ \\
\hline \multicolumn{2}{|l|}{ Patient sex, n (\%) ${ }^{a}$} \\
\hline Female & $224(33.8)$ \\
\hline Male & $438(66.2)$ \\
\hline \multicolumn{2}{|l|}{ Patient age, $\mathrm{n}(\%)^{\mathrm{a}}$} \\
\hline$<13$ & $31(4.8)$ \\
\hline $13-24$ & $214(32.9)$ \\
\hline $25-40$ & $252(38.8)$ \\
\hline$>40$ & $153(23.5)$ \\
\hline \multicolumn{2}{|l|}{ Patient origin, $n(\%)^{a}$} \\
\hline Addis Ababa & 259 (39.4) \\
\hline Outside Addis & $398(60.6)$ \\
\hline \multicolumn{2}{|l|}{ Date of Arrival, n (\%) ${ }^{\mathrm{a}}$} \\
\hline Weekday & $467(72.4)$ \\
\hline Weekend & $178(27.6)$ \\
\hline \multicolumn{2}{|l|}{ Triage Acuity, n (\%) $)^{a, b, c}$} \\
\hline Low acuity & $289(44.7)$ \\
\hline Moderate acuity & $273(42.2)$ \\
\hline High acuity & $85(13.1)$ \\
\hline \multicolumn{2}{|l|}{ Referral status/source, n (\%) } \\
\hline Not referred (from scene) & $211(34.1)$ \\
\hline Referred from government hospital & $263(42.5)$ \\
\hline Referred from health center & $126(20.3)$ \\
\hline Referred from private institution & $19(3.1)$ \\
\hline \multicolumn{2}{|l|}{ Ref. communication, n (\%) } \\
\hline Yes (before arrival) & $224(57.7)$ \\
\hline No & $164(42.3)$ \\
\hline \multicolumn{2}{|l|}{ Mode of arrival $^{a}$} \\
\hline Ambulance & $366(59.0)$ \\
\hline Taxi or private car & $234(37.7)$ \\
\hline Walking or being carried & $20(3.2)$ \\
\hline
\end{tabular}

apercent of non-missing data reported. Missing data per variable as follows: sex $(n=0 / 662 ; 0 \%)$, age $(n=12 / 662 ; 1.8 \%)$, patient origin $(5 / 662 ; 0.8 \%)$, date of arrival $(17 / 662 ; 2.6 \%)$, triage acuity $(15 / 662 ; 2.3 \%)$, referral status/source $(43 / 662 ; 6.5 \%)$, referral communication $(20 / 408 ; 4.9 \%)$, mode of arrival $(42 / 662 ; 6.3 \%)$

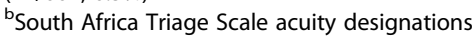

'High acuity includes very urgent (58/647; 9.0\%), Emergent (25/647; 3.8\%) and Dead on arrival $(2 / 647 ; 0.3 \%)$. Dead on arrival grouped within very urgent or emergent due to presumed scene/pre-hospital acuity

${ }^{d}$ Subset of referred patients only

\section{Inter-facility communication}

Despite the high frequency of RTC referrals, overall communication from referring institutions to AaBET Hospital was poor. Among all RTC patients referred from other health institutions, more than two in five $(164 / 388 ; 42.3 \%)$ arrived with no prior notification 
Table 2 RTC patient factors associated with referral to AaBET Hospital, Addis Ababa

\begin{tabular}{|c|c|c|c|}
\hline \multirow[t]{3}{*}{ Characteristic } & \multicolumn{2}{|c|}{ Referral status } & \multirow{2}{*}{$\begin{array}{l}\text { Adjusted odds } \\
\text { of referral }\end{array}$} \\
\hline & $\begin{array}{l}\text { Referred } \\
(n=408)\end{array}$ & $\begin{array}{l}\text { Not Referred } \\
(n=211)\end{array}$ & \\
\hline & $N(\%)^{a}$ & $N(\%)^{\mathrm{a}}$ & aOR $(95 \% C l)$ \\
\hline \multicolumn{4}{|l|}{ Patient sex } \\
\hline Female & $138(33.8)$ & $78(37.0)$ & 1.0 (ref) \\
\hline Male & $270(66.2)$ & $133(63.0)$ & $1.11(0.76-1.63)$ \\
\hline \multicolumn{4}{|l|}{ Patient age } \\
\hline$<13$ & $23(5.7)$ & $8(3.9)$ & $1.03(0.39,2.67)$ \\
\hline $13-24$ & $122(30.2)$ & $78(38.2)$ & $0.62(0.38,1.03)$ \\
\hline $25-40$ & $162(40.1)$ & $74(36.3)$ & $0.86(0.53,1.42)$ \\
\hline$>40$ & $97(24.0)$ & 44 (21.6) & 1.0 (ref) \\
\hline \multicolumn{4}{|l|}{ Patient origin } \\
\hline Addis Ababa & $111(27.5)$ & $138(65.4)$ & $0.22(0.15,0.32)$ \\
\hline Outside Addis & $292(72.5)$ & 73 (34.6) & 1.0 (ref) \\
\hline \multicolumn{4}{|l|}{ Date of Arrival } \\
\hline Weekday & $290(72.9)$ & $141(68.8)$ & $1.02(0.68,1.54)$ \\
\hline Weekend & $108(27.1)$ & $64(31.2)$ & 1.0 (ref) \\
\hline \multicolumn{4}{|l|}{ Triage Acuity ${ }^{b, c}$} \\
\hline Low Acuity & 157 (39.6) & $119(57.2)$ & 1.0 (ref) \\
\hline Moderate Acuity & $178(44.9)$ & $73(35.1)$ & $1.55(1.05,2.28)$ \\
\hline High Acuity & $61(15.4)$ & $16(7.7)$ & $2.20(1.16,4.17)$ \\
\hline \multicolumn{4}{|l|}{ Referral status/source } \\
\hline Not referred (from scene) & N/A & $211(100)$ & $\mathrm{N} / \mathrm{A}$ \\
\hline $\begin{array}{l}\text { Referred from } \\
\text { government hospital }\end{array}$ & $263(64.5)$ & E N/AEN & $\mathrm{N} / \mathrm{A}$ \\
\hline $\begin{array}{l}\text { Referred from health } \\
\text { center }\end{array}$ & $126(30.9)$ & NE N/A N & N/A \\
\hline $\begin{array}{l}\text { Referred from private } \\
\text { institution }\end{array}$ & $19(4.7)$ & NE N/A N & $\mathrm{N} / \mathrm{A}$ \\
\hline
\end{tabular}

apercent of non-missing data reported

${ }^{\mathrm{b}}$ South Africa Triage Scale acuity designations

'High acuity includes very urgent, emergent, and dead on arrival. Dead on arrival grouped within very urgent or emergent due to presumed scene/pre-hospital acuity

from the referring facility (Table 1). Communication was most likely to occur on weekdays (aOR 1.74, $95 \%$ CI 1.06-2.85), when health facility staffing is highest. Rates of communication were similar between patients referred from within $(64 / 104 ; 61.5 \%)$ and from outside $(156 / 279 ; 55.9 \%)$ Addis Ababa, and did not significantly differ according to the type of referring institution. Interestingly, despite higher acuity among referred RTC patients than those not referred, communication from transferring facilities was no higher among the most ill than the least (aOR 0.98, 95\%CI 0.49-1.94), nor among those sent by ambulance (aOR 1.46, 95\%CI $0.88-2.43$ ) (Table 3).
Table 3 RTC patient factors associated with inter-facility referral communication, AaBET Hospital, Addis Ababa

\begin{tabular}{|c|c|c|c|}
\hline \multirow[t]{3}{*}{ Characteristic } & \multicolumn{2}{|c|}{ Referral communication } & \multirow{2}{*}{$\begin{array}{l}\text { Adjusted odds of } \\
\text { communication }\end{array}$} \\
\hline & $\begin{array}{l}\text { Yes } \\
(n=224)\end{array}$ & $\begin{array}{l}\text { No } \\
(n=164)\end{array}$ & \\
\hline & $N(\%)^{a}$ & $N(\%)^{a}$ & $a O R(95 \% C l)$ \\
\hline \multicolumn{4}{|l|}{ Patient sex } \\
\hline Female & $82(36.6)$ & $50(30.5)$ & 1.0 (ref) \\
\hline Male & $142(63.4)$ & $114(69.5)$ & $0.69(0.43,1.12)$ \\
\hline \multicolumn{4}{|l|}{ Patient age } \\
\hline$<13$ & $11(5.0)$ & $12(7.3)$ & $0.73(0.27,1.97)$ \\
\hline $13-24$ & $66(30.0)$ & $50(30.5)$ & $0.98(0.54,1.79)$ \\
\hline $25-40$ & $93(42.3)$ & $61(37.2)$ & $1.38(0.78,2.45)$ \\
\hline$>40$ & $50(22.7)$ & $41(25.0)$ & 1.0 (ref) \\
\hline \multicolumn{4}{|l|}{ Patient origin } \\
\hline Addis Ababa & $64(29.1)$ & $40(24.5)$ & $1.32(0.79,2.20)$ \\
\hline Outside Addis & $156(70.9)$ & $123(75.5)$ & 1.0 (ref) \\
\hline \multicolumn{4}{|l|}{ Date of Arrival } \\
\hline Weekday & $171(77.7)$ & $104(65.4)$ & $1.74(1.06,2.85)$ \\
\hline Weekend & $49(22.3)$ & $55(34.6)$ & 1.0 (ref) \\
\hline \multicolumn{4}{|l|}{ Triage Acuity ${ }^{\mathrm{b}, \mathrm{c}}$} \\
\hline Low Acuity & 85 (38.8) & $61(38.9)$ & 1.0 (ref) \\
\hline Moderate Acuity & $102(46.6)$ & 69 (43.9) & $1.11(0.68,1.79)$ \\
\hline High Acuity & $32(14.6)$ & $27(17.2)$ & $0.98(0.49,1.94)$ \\
\hline \multicolumn{4}{|l|}{ Referral source } \\
\hline $\begin{array}{l}\text { Referred from } \\
\text { government hospital }\end{array}$ & $130(58.0)$ & $121(73.8)$ & $0.55(0.18,1.68)$ \\
\hline $\begin{array}{l}\text { Referred from health } \\
\text { center }\end{array}$ & $80(35.7)$ & $38(23.2)$ & $1.15(0.36,3.72)$ \\
\hline $\begin{array}{l}\text { Referred from private } \\
\text { institution }\end{array}$ & $14(6.2)$ & $5(3.0)$ & 0 (ref) \\
\hline \multicolumn{4}{|l|}{ Mode of arrival (transport) } \\
\hline Ambulance & $136(66.0)$ & $121(77.6)$ & 0 (ref) \\
\hline No ambulance & $70(34.0)$ & 35 (22.4) & $1.46(0.88,2.43)$ \\
\hline
\end{tabular}

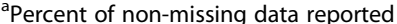

bouth Africa Triage Scale acuity designations

'High acuity includes very urgent, emergent, and dead on arrival. Dead on arrival grouped within very urgent or emergent due to presumed scene/pre-hospital acuity

\section{Mode of arrival}

The vast majority (96.7\%) of RTC patients arrived at AaBET hospital by vehicle, including over half $(59.0 \%)$ by ambulance (Table 1). Regardless of other characteristics, patients were more likely to arrive by ambulance if coming from another government hospital than from the scene itself (aOR 4.23, 95\%CI 2.63-6.78; Table 4). However, ambulance use did not differ significantly based on the day of patients' arrival, nor whether they originated from within or outside Addis Ababa. Importantly, patients with highest acuity were not more likely to arrive by ambulance than those with lowest severity 
Table 4 RTC patient factors associated with ambulance arrival, AaBET Hospital, Addis Ababa

\begin{tabular}{|c|c|c|c|}
\hline \multirow[t]{3}{*}{ Characteristic } & \multicolumn{2}{|c|}{ Arrival by ambulance } & \multirow{2}{*}{$\begin{array}{l}\text { Adjusted odds } \\
\text { of ambulance use }\end{array}$} \\
\hline & Yes $(n=366)$ & No $(n=254)$ & \\
\hline & $N(\%)^{\mathrm{a}}$ & $N(\%)^{\mathrm{a}}$ & $a O R(95 \% C l)$ \\
\hline \multicolumn{4}{|l|}{ Patient sex } \\
\hline Female & $139(38.0)$ & $74(29.1)$ & $1.0(r e f)$ \\
\hline Male & $227(62.0)$ & 180 (70.9) & $0.63(0.43,0.91)$ \\
\hline \multicolumn{4}{|l|}{ Patient age } \\
\hline$<13$ & $19(5.3)$ & $12(4.8)$ & $0.77(0.32,1.86)$ \\
\hline $13-24$ & $115(31.9)$ & $83(33.3)$ & $1.21(0.75,1.95)$ \\
\hline $25-40$ & $145(40.2)$ & $93(37.3)$ & $1.15(0.73,1.82)$ \\
\hline$>40$ & $82(22.7)$ & $61(24.5)$ & $1.0(r e f)$ \\
\hline \multicolumn{4}{|l|}{ Patient origin } \\
\hline Addis Ababa & $121(33.4)$ & 119 (46.9) & $0.78(0.53,1.13)$ \\
\hline Outside Addis & $241(66.6)$ & $135(53.1)$ & 1.0 (ref) \\
\hline \multicolumn{4}{|l|}{ Date of Arrival } \\
\hline Weekday & $257(72.6)$ & $177(70.8)$ & $1.05(0.71,1.55)$ \\
\hline Weekend & 97 (27.4) & $73(29.2)$ & 1.0 (ref) \\
\hline \multicolumn{4}{|l|}{ Triage Acuity ${ }^{b, c}$} \\
\hline Low Acuity & $145(41.1)$ & $132(52.2)$ & 1.0 (ref) \\
\hline Moderate Acuity & $155(43.9)$ & 97 (38.3) & $1.34(0.92,1.95)$ \\
\hline High Acuity & $53(15.0)$ & $24(9.5)$ & $1.56(0.86,2.84)$ \\
\hline \multicolumn{4}{|l|}{ Referral status/source } \\
\hline $\begin{array}{l}\text { Referred from } \\
\text { government hospital }\end{array}$ & $191(54.6)$ & 55 (23.9) & $4.23(2.63,6.78)$ \\
\hline $\begin{array}{l}\text { Referred from health } \\
\text { center }\end{array}$ & 68 (19.4) & $51(22.2)$ & $1.61(0.97,2.69)$ \\
\hline $\begin{array}{l}\text { Referred from private } \\
\text { institution }\end{array}$ & $7(2.0)$ & $9(3.9)$ & $0.88(0.29,2.69)$ \\
\hline Self-Referral/Scene & $84(24.0)$ & $115(50.0)$ & 1.0 (ref) \\
\hline
\end{tabular}

apercent of non-missing data reported

${ }^{\mathrm{b}}$ South Africa Triage Scale acuity designations

'High acuity includes very urgent, emergent, and dead on arrival. Dead on arrival grouped within very urgent or emergent due to presumed scene/pre-hospital acuity

injuries (aOR 1.56, 95\% CI 0.86-2.84). Interestingly, males were less likely to arrive by ambulance after RTC than their female counterparts (aOR 0.63, 95\% CI 0.43-0.91), independent of other factors.

\section{Discussion}

Road traffic collisions are a leading cause of morbidity and mortality worldwide and particularly in sub-Saharan Africa, where growth in motorization has outpaced efforts to implement and enforce RTC prevention interventions [1]. Estimated annual African RTC fatality rates (26 per 100,000 population) are twice those in the United States and three times greater than in Europe [1]. In Ethiopia, RTC fatality rates are among the continent's highest [18].
The alarming burden of RTC has attracted mounting international attention in recent years. The United Nations General Assembly declared 2011-2020 the Decade of Action for road safety [2], while the body's Sustainable Development Goals (SDGs), ratified unanimously in 2015 , called for $50 \%$ fewer RTC deaths and injuries by 2020 [19]. A number of national and local policy efforts have been implemented toward this end $[20,21]$. These have mostly included legislative regulations, educational interventions, law enforcement, infrastructural reform, and community-based prevention programs [21]. At the same time, a growing number of sub-Saharan African trauma registries have aimed to provide clinicians, researchers, and administrators clearer data regarding local burden of traumatic illness [18, 22, 23].

Despite positive trends in growing global attention to RTC, surprisingly little focus has been placed on evaluating and improving formal pre-hospital trauma systems in low-income settings. Most trauma deaths occur in the pre-hospital setting, and the percent who die before reaching a hospital is highest in low-income settings where formal pre-hospital systems are weakest [24]. Most studies evaluating ambulance use after RTC have described the frequency of use [25-29], rather than independent predictors of use. Knowing which patients currently receive ambulance transport after RTC is essential to developing policies to direct its use given relative scarcity and cost compared to other modes of transport.

In our study of over six hundred RTC patients arriving to a single tertiary trauma referral hospital in Addis Ababa, Ethiopia, a higher percentage of patients arrived by ambulance (59\%) compared to other published studies from elsewhere across Africa [7, 8, 25-27]. Such disparities in ambulance utilization are likely multifactorial. Our methodological decision to focus exclusively on RTC rather than all trauma patients resulted in our exclusion of large numbers of violent trauma victims transported by police, accounted for in other studies [7]. In addition, Ethiopian governmental efforts to coordinate and concentrate specialty care across city public hospitals in Addis Ababa means AaBET Hospital is one of only two major trauma centers citywide, receiving a higher proportion of regional trauma referrals than reported elsewhere [25-27]. Finally, as one of the first African countries to prioritize emergency care specialization and specialty training [28-30], Ethiopia has also placed comparatively large emphasis on formal prehospital infrastructure and training. Large ambulance provisions by the federal government have supplemented private and non-governmental pre-hospital organizations already in practice [31], while a regional emergency medical dispatch phone line enables easy public ambulance access. These factors may have contributed to increased ambulance availability. 
Even accounting for higher rates of ambulance use, our findings highlight several important yet concerning trends that warrant further attention in other settings. Importantly, we found that ambulance use among RTC patients arriving to AaBET Hospital was not significantly associated with triage acuity. This is in contrast to prior work among both trauma and non-trauma patients in Ghana [32], and suggests that ambulance adoption in lower-income urban settings may not always naturally align with patient clinical needs. RTC patients with high acuity need time-sensitive stabilization and are at greatest risk of mortality, disability, or hospital admission, yet in our population were no more likely to receive ambulance transport than those with minimal injury burden. There are several possible explanations for this. While these findings may reflect persistent pervasive public unawareness regarding ambulance services or public ambulance avoidance due to fear of financial liability, we instead suspect they represent a discrepancy in the extent to which patient acuity influences ambulance selection among referred and non-referred populations.

To better test this hypothesis, we performed separate subgroup analyses assessing ambulance use among referred and non-referred populations (i.e., effect modification). Results did not change among patients referred to AaBET from another institution; patients with high and moderate acuity were no more likely to be transported by ambulance than those with low acuity (Additional file 1: Table S1). Similarly, among patients arriving directly from the scene, those with high acuity were not more likely to receive ambulance transport than those with low acuity (Additional file 2: Table S2). However, those with moderate acuity from the scene were nearly three times more likely to arrive by ambulance than those with low acuity (aOR 2.97, 95\%CI 1.50-5.86). This finding is important, and suggests that transportation decisions made at the scene may be influenced by patient acuity. In light of this, lower rates of ambulance transportation among high-acuity patients at the scene may reflect lay first responders' preferential selection of immediate on-site (lay) transportation for the sickest patients deemed unable to wait for ambulance arrival. By contrast, we found no evidence to suggest that acuity influenced ambulance decisions made by referring providers-consistent as well with poor inter-facility communication (58\%), even for the sickest patients.

In low-income countries, ambulances remain scare resources but possess key benefits over pre-hospital lay transportation in the appropriate clinical settings. Given the relative expense of ambulances in such settings, maximizing their value is essential, and will depend on judicious use in accordance with patient clinical needs. When assessed alongside contrasting work from Ghana [32], our findings suggest heterogeneity in post-traumatic ambulance utilization patterns in sub-Saharan Africa, and highlight the need for locally-driven assessments to ensure value-directed care. Furthermore, our data suggest that in promoting appropriate ambulance use, training of healthcare providers may be equally important as ongoing lay education. Inappropriate inter-facility ambulance use for patients deemed low-acuity after clinician evaluation offers few benefits over lay transportation, while limiting ambulance availability in higher-acuity settings elsewhere. When ambulances are free to respond in a timely fashion to high-acuity patients, a greater proportion of these patients may be brought directly from the scene to trauma centers like AaBET Hospital, bypassing outside institutions with little or no trauma expertise and improving mortality [33]. In our study, 103 low-acuity patients received ambulance transport from another facility (40\% of all referred patients transported by ambulance), while one third (40) of high- and moderate-acuity patients arrived from the scene by other means (Additional file 1: Table S1 and Additional file 2: Table S2).

We suggest that countries like Ethiopia that seek to develop formal pre-hospital ambulance transportation systems should develop measures to ensure this scarce pre-hospital resource is available to be used when and where it is of highest value. Such measures could include guidelines on inter-facility ambulance use in specific clinical settings (e.g., trauma), auditing of referring providers and institutions to identify variability and opportunities for targeted intervention, or regional regulations. Such measures might be best implemented by different stakeholders, including institutions, ambulance providers, or regional governments. In some cases, it may be necessary to modify existing guidelines, including those that may inadvertently pressure providers to refer lower-acuity trauma patients [32]. Once ambulances are freed from lower-acuity referral demand, clinical and geospatial dispatch algorithms might be employed to best allocate them among patients arriving from the scene [34].

\section{Limitations}

Our study has several limitations. As a single-center crosssectional assessment, our findings may not generalize to other settings, including to rural or district-level hospitals, private facilities, and those that are not regional referral or specialty centers of excellence. Moreover, the high rates of referral among RTC patients and the relative abundance of ambulances we observed may limit replicability where prehospital and emergency health systems are organized differently or at different stages of development.

Because we employed ED triage records, we are inherently constrained in the inferences we are able to draw. Specifically, we are unable to draw conclusions regarding specific types of injuries, treatments obtained, clinical outcomes, or costs of care. In addition, we are unable to examine reasons underlying ambulance use decisions 
among providers or patients/laypersons, nor can we deduce appropriateness of referral decision in the first place. Several of these questions might be best explored through future survey-based and qualitative designs [35]. Nevertheless, our findings suggest considerable opportunities for improvement in local regional trauma system coordination, and highlight the utility of ED triage data as a feasible, low-cost, and efficient means of monitoring local pre-hospital use and referral patterns.

\section{Conclusions}

As urban trauma and pre-hospital care systems mature across sub-Saharan Africa, regional governments and health policymakers should regularly and critically evaluate whether limited resources are being directed to those patients most likely to benefit. In Addis Ababa, ambulance use does not appear to parallel clinical acuity among patients presenting after RTC. Further studies should explore ambulance use in other contexts, as well as factors influencing ambulance selection for low-acuity patients. Reducing ambulance use among low-acuity inter-facility referrals may represent a targetable opportunity to increase ambulance value where they are scarcest.

\section{Additional files}

Additional file 1: Table S1. Factors associated with ambulance arrival among RTC patients referred from another institution, AaBET Hospital, Addis Ababa. (DOCX 15 kb)

Additional file 2: Table S2. Factors associated with ambulance arrival among RTC patients arriving from the scene, AaBET Hospital, Addis Ababa. (DOCX 14 kb)

\section{Abbreviations}

AaBET: Addis Ababa Burn Emergency and Trauma (Hospital); aOR: Adjusted odds ratio; Cl: Confidence interval; ED: Emergency department; ICU: Intensive care unit; LMIC: Low- and middle-income; RTC: Road traffic collisions; SATS: South Africa triage scale; SDGs: Sustainable development goals; SPHMMC: St. Paul's Hospital Millennium Medical College; SPSS: Statistical Package for the Social Sciences

\section{Acknowledgements}

Authors are grateful to St. Paul's Hospital Millennium Medical College for technical and financial support, and to AaBET hospital senior managements and triage officers for facilitating data collection.

\section{Funding}

This study was funded by St. Paul's Hospital Millennium Medical College, Addis Ababa, Ethiopia. The college didn't involve in the study design, data collection, analysis and reporting.

\section{Availability of data and materials}

The datasets used and/or analyzed during the current study are available from the corresponding author on reasonable request.

\section{Authors' contributions}

YA and TD designed the study. YA collected study data. YA and EY analyzed the data. All authors participated in data interpretation. YA and DS wrote the manuscript. All authors contributed critical revisions to the report, and all approved the final version.

\section{Ethics approval and consent to participate}

The study was approved by the Institutional Review Board of St. Paul's Hospital Millennium Medical College, with informed consent waived based on study design.

\section{Consent for publication}

Not applicable.

Competing interests

The authors declare that they have no competing interests.

\section{Publisher's Note}

Springer Nature remains neutral with regard to jurisdictional claims in published maps and institutional affiliations.

\section{Author details}

${ }^{1}$ Department of Emergency and Critical Care Nursing, St. Paul's Hospital Millennium Medical College, Addis Ababa, Ethiopia. ${ }^{2}$ School of Allied Health Sciences, College of Health Sciences, Addis Ababa University, Addis Ababa, Ethiopia. ${ }^{3}$ Robinson Research Institute, School of Medicine, The University of Adelaide, Adelaide, Australia. ${ }^{4}$ National Clinician Scholars Program and Department of Emergency Medicine, Yale School of Medicine, New Haven, USA.

Received: 22 November 2017 Accepted: 6 February 2018

Published online: 13 February 2018

\section{References}

1. World Health Organization. Global status report on road safety. Geneva, Switzerland: WHO; 2015.

2. World Health Organization. Global plan for the decade of action for road safety 2011-2020 Geneva, WHO

3. Merchant A, Outhay M, Gonzaléz-Calvo L, Moon TD, Sidat M, Taibo CLA, McQueen K. Training laypersons and hospital personnel in basic resuscitation techniques: an approach to impact the global trauma burden in Mozambique. World J Surg. 2015:39(6):1433-7.

4. Benie Bi Vroh J, Tiembre I, Ekra DK, Ano Ama MN, Ka OM, Ncho Dagnan S, Tagliante-Saracino J. Determinants of fatal road traffic injuries in cote d'Ivoire from 2002 to 2011. Sante Publique. 2016;28(5):647-53.

5. Chandrasekharan A, Nanavati AJ, Prabhakar S, Prabhakar S. Factors impacting mortality in the pre-hospital period after road traffic accidents in urban India. Trauma Mon. 2016;21(3):e22456.

6. Kobusingye OC, Hyder AA, Bishai D, Hicks ER, Mock C, Joshipura M. Emergency medical systems in low- and middle-income countries: recommendations for action. Bull World Health Organ. 2005;83(8):626-31.

7. Hsia RY, Ozgediz D, Mutto M, Jayaraman S, Kyamanywa P, Kobusingye OC. Epidemiology of injuries presenting to the national hospital in Kampala, Uganda: implications for research and policy. Int J Emerg Med. 2010;3(3):165-72.

8. Seid M, Azazh A, Enquselassie F, Yisma E. Injury characteristics and outcome of road traffic accident among victims at adult emergency Department of Tikur Anbessa specialized hospital, Addis Ababa, Ethiopia: a prospective hospital based study. BMC Emerg Med. 2015;15(1):10.

9. Bruijns SR, Wallis LA, Burch VC. A prospective evaluation of the cape triage score in the emergency department of an urban public hospital in South Africa. Emerg Med J. 2008;25(7):398-402.

10. Twomey M, Wallis LA, Thompson ML, Myers JE. The South African triage scale (adult version) provides reliable acuity ratings. Int Emerg Nurs. 2012;20(3):142-50

11. Dalwai MK, Twomey M, Maikere J, Said S, Wakee M, Jemmy J-P, Valles P, Tayler-Smith K, Wallis L, Zachariahi R. Reliability and accuracy of the south African triage scale when used by nurses in the emergency Department of Timergara Hospital, Pakistan. S Afr Med J. 2014;104:372-5.

12. Rominski S, Bell SA, Oduro G, Ampong P, Oteng R, Donkor P. The implementation of the south African triage score (SATS) in an urban teaching hospital, Ghana. Afr J Emerg Med. 2014;4(2):71-5.

13. Twomey $M$, Cheema $B$, Buys $H$, Cohen $K$, de Sà $A$, Louw $P$, Ismail $M$ Finlayson $\mathrm{H}$, Cunningham $\mathrm{C}$, Westwood A. Vital signs for children at triage: a multicentre validation of the revised south African triage scale (SATS) for children. S Afr Med J. 2013;103:304-8. 
14. Twomey M, de Sá A, Wallis LA, Myers JE. Inter-rater reliability of the south African triage scale: assessing two different cadres of health care workers in a real time environment. Afr J Emerg Med. 2011;1(3):113-8.

15. Lowsby R, Kamara C, Kamara M, Nyhus H, Williams N, Bradfield M, Harrison $\mathrm{H}$-L. An assessment of nurse-led triage at Connaught hospital, Sierra Leone in the immediate post-Ebola period. Afr J Emerg Med. 2017;7(2):51-5.

16. Gardner A, Forson PK, Oduro G, Stewart B, Dike N, Glover P, Maio RF. Diagnostic accuracy of the Kampala trauma score using estimated abbreviated injury scale scores and physician opinion. Injury. 2017;48(1):177-83.

17. Nagurney JT, Brown DFM, Sane S, Weiner JB, Wang AC, Chang Y. The accuracy and completeness of data collected by prospective and retrospective methods. Acad Emerg Med. 2005;12(9):884-95.

18. Adeloye DTJ, Akanbi MA, et al. The burden of road traffic crashes, injuries and deaths in Africa: a systematic review and meta-analysis. Bull World Health Organ. 2016;94:510-21A.

19. United Nations. Resolution adopted by the General Assembly on 25 September 2015: Transforming our world: the 2030 Agenda for Sustainable Development. Washington; United Nations; 2015. [undocs.org/A/RES/70/1].

20. LaGrone LRK, Joshipura M, et al. Uptake of the World Health Organization's trauma care guidelines: a systematic review. Bull World Health Organ. 2016;94:585-98C.

21. Staton C, Vissoci J, Gong E, Toomey N, Wafula R, Abdelgadir J, Zhou Y, Liu C, Pei F, Zick B, et al. Road traffic injury prevention initiatives: a systematic review and Metasummary of effectiveness in low and middle income countries. PLoS One. 2016;11(1):e0144971.

22. Boughton $\mathrm{O}$, Jones $\mathrm{GG}$, Lavy $\mathrm{CBD}$, Grimes $\mathrm{CE}$. Young, male, road traffic victims: a systematic review of the published trauma registry literature from low and middle income countries. SICOT-J. 2015;1:10.

23. Vissoci JRN, Shogilev DJ, Krebs E, Ld A, Vieira IF, Toomey N, Portero Batilana A Haglund M, Staton CA. Road traffic injury in sub-Saharan African countries: a systematic review and summary of observational studies. Traffic Inj Prev. 2017; 18(7):767-73.

24. Mock CN, Jurkovich GJ, nii-Amon-Kotei D, Arreola-Risa C, Maier RV. Trauma mortality patterns in three nations at different economic levels: implications for global trauma system development. J Trauma Acute Care Surg. 1998;44(5):804-14.

25. Ahidjo KA, Olayinka SA, Ayokunle O, Mustapha AF, Sulaiman GAA, Gbolahan AT. Prehospital transport of patients with spinal cord injury in Nigeria. J Spinal Cord Med. 2011;34(3):308-11.

26. Ibrahim NA, Ajani AWO, Mustafa IA, Balogun RA, Oludara MA, Idowu OE, Solagberu BA. Road traffic injury in Lagos, Nigeria: assessing prehospital care. Prehosp Disast Med. 2017;32(4):424-30.

27. Mowafi H, Oranmore-Brown R, Hopkins KL, White EE, Mulla YF, Seidenberg P. Analysis of prehospital transport use for trauma patients in Lusaka, Zambia. World J Surg. 2016;40(12):2868-74.

28. Azazh A, Teklu S, Woldetsadi A, Seyoum N, Geremew H, Busse H, Tefera G, Wubben R, Rankin P, Tupesis JP, et al. Emergency medicine and its development in Ethiopia with emphasis on the role of Addis Ababa University, School of Medicine, emergency medicine department. Ethiop Med J. 2014;(Suppl 2):1-12.

29. Busse H, Azazh A, Teklu S, Tupesis JP, Woldetsadik A, Wubben RJ, Tefera G. Creating change through collaboration: a twinning partnership to strengthen emergency medicine at Addis Ababa University/Tikur Anbessa specialized hospital — a model for international medical education partnerships Generación Cambios a través de la Colaboración: un Acuerdo de Asociación para Fortalecer la Medicina de Urgencias y Emergencias de la Universidad de Addis Ababa y el Hospital Especializado Tikur Anbessa. Acad Emerg Med. 2013;20(12):1310-8.

30. W/Tsadik A, Azazh A, Teklu S, Seyum N, Geremew H, Rankin P, Erschen MJ. Development of emergency medicine and critical care masters program for nurses at Addis Ababa University, School of Medicine. Ethiop Med J. 2014;(Suppl 2):21-6.

31. Directorate MS: Emergency medical services: timely delivery of life saving medical interventions. Federal Ministry of Health 16th National Annual Review Meeting Group Discussion. ARM16-doc 12/14. 2014

32. Nee-Kofi Mould-Millman C, Rominski S, Oteng R. Ambulance or taxi? High acuity prehospital transports in the Ashanti region of Ghana. Afr J Emerg Med. 2014;4(1):8-13.

33. Boschini LP, Lu-Myers Y, Msiska N, Cairns B, Charles AG. Effect of direct and indirect transfer status on trauma mortality in sub Saharan Africa. Injury. 2016;47(5):1118-22.
34. Ohshige K, Kawakami C, Mizushima S, Moriwaki Y, Suzuki N. Evaluation of an algorithm for estimating a patient's life threat risk from an ambulance call. BMC Emerg Med. 2009;9(1):21.

35. Chandran A, Ejaz K, Karani R, Baqir M, Razzak J, Hyder AA. Insights on the effects of patient perceptions and awareness on ambulance usage in Karachi, Pakistan. Emerg Med J. 2014;31:990-993.

\section{Submit your next manuscript to BioMed Central and we will help you at every step:}

- We accept pre-submission inquiries

- Our selector tool helps you to find the most relevant journal

- We provide round the clock customer support

- Convenient online submission

- Thorough peer review

- Inclusion in PubMed and all major indexing services

- Maximum visibility for your research

Submit your manuscript at www.biomedcentral.com/submit

) Biomed Central 